\title{
Investigation in dynamics of sowing machine-tractor assembly unit
}

Antoshchenkov R.

P. Vasylenko Kharkiv national engineering university of agriculture, Alchevskykh Str., 44, Kharkiv, 61000, Ukraine; e-mail: roman.antoshchenkov@gmail.com

The purpose. To study efficiency of use of sowing machine-tractor assembly unit using theoretical and experimental dynamic and power indexes. Methods. Classical mechanics, mathematical simulation, solution of systems of nonlinear differential equations. Experimental researches were lead with application of physical simulation and tests. Results. Three-mass dynamic model of plane-parallel movement of multiple-elements machine-tractor sowing unit in structure of tractor of classical arrangement HTZ-16131 and soil-cultivating unit APP-6 was made. Dynamic model had one degree of freedom. The event was considered of movement of assembly unit at which the angle of rotation of steered wheels was set according to sinusoidal (harmonic) law. Angles of rotation, speeds of movement and forces acting on elements of the assembly unit were calculated. The measuring system of dynamics and energetic of mobile machines was developed for holding experimental researches. The system is designed for determination of kinematic, dynamic, capacity and power characteristics of mobile machines and their elements at road, field and benchmark testing. An innovative component of measuring system is the method of determination of slippage of wheels or driving sprockets. It consists in determination of speed of twirl of the wheel by means of gyroscope and accelerometer. Results of experimental researches which have confirmed adequacy of mathematical model of dynamics of the assembly unit are gained. Conclusions. Angles of rotation of elements of the assembly unit looked like sinus-wave oscillations. It was established that seeder had low average speed of movement and the greatest range of vacillating. During experimental researches of the assembly unit it was established that it works in satisfactory conditions.

Key words: machine-tractor assembly unit, dynamics, theoretical studies, measuring system, experiment.

DOI: https://doi.org/10.31073/agrovisnyk201905-05

The current state of Ukraine's agricultural sector needs to improve the efficiency of crop production, which in turn depends on the energy consumption for its implementation. Reducing energy costs is achieved by the combined use of modern agricultural units, which are to provide quality improvement implementation process, reducing the amount of used fuel and lubricants, reducing the number of passes across the field, improving the quality of working conditions of the operators. Combined agricultural units represent a complex agricultural machinery for different manufacturing operations, connected in a multiple unit. Ways of units offered by the manufacturer. Dynamics multiple units requires in-depth research to determine the best and least costly modes. But the variety of structures multiple units increases the time spent on their research. Since, in the study of the dynamics of the combined agricultural units as multiple (multibody) mechanical systems, it is necessary to solve a scientific problem dynamic while moving three Cartesian coordinates of a random combination of the system. The study of the dynamics of these systems requires the development of methodology formation dynamics equations to the changing structures and options to connect machines and units. Existing methodology formation dynamics equations machine and tractor units (MTU) cannot be used during the study units with variable structures

Analysis of recent research and publications. Mathematical models used to study the dynamics of multiple combined units mainly take into account the movement in one plane [1-3]. During the investigation of plane-parallel movement dynamics are considered problem [4], stability and control of machine-tractor units and straightness of rows of crops. Accordingly, the effect of supporting surface irregularities and vibrations in the elements of the unit investigated longitudinal vertical plane [5]. Mutual influence the 
dynamics in two dimensions by the example of the combined-cultivating sowing units not previously been investigated. To build dynamics equations machine and tractor units apply the principle of D'AlembertLagrange equation Lagrange or 2nd kind [6]. Question sown block units depending on its design studied in [7]. However, the aim of the study - efficiency sowing tractor unit by means of theoretical and experimental studies of dynamic and energetic performance.

Methods. During the study used methods of classical mechanics, mathematical modeling, solving systems of nonlinear differential equations. Experimental studies conducted using physical modeling and testing.

The results of research. To solve scientific problems efficiently use multiple machine-tractor units necessary to investigate and determine the dynamics of the relationship between dynamic power and performance of their operation. The variety of designs and technological schemes of different ways aggregation need to increase the number of mathematical models to study the dynamics and effectiveness of their use. Methodology study the dynamics of multiple farm units proved in [8].

A three-mass dynamic model of plane-parallel movement multielement MTA for example seed tractor unit composed classic layout KHTZ-16131 - cultivating and sowing aggregate APP-6 (Fig. 1).

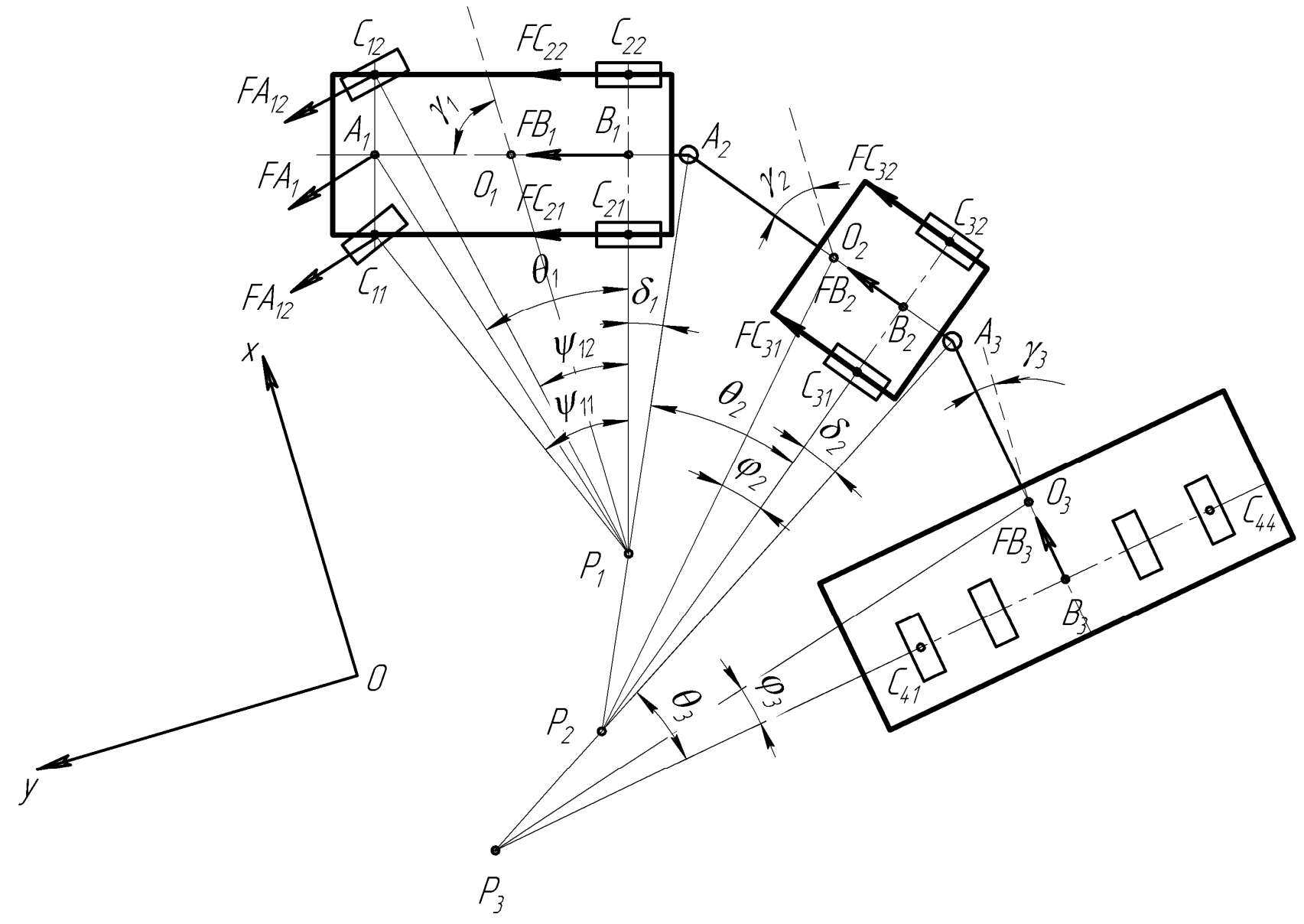

Fig. 1. Dynamic model tractor unit

pp. $C_{i j}$ - centers of the wheels ( $i-$ point number, $j-$ number in the series); p. $A_{k}$ - point front frame (k $=1,2,3$, for three-element unit); p. $O_{k}$ - centers of mass of the tractor, bunkers and machine; $m_{k}, J_{k}-$ mass and moment of inertia of the element unit; p. $B_{k}$ - the mid-point of the rear axle of the tractor, bunkers and machine; p. $P_{k}-$ instant center velocity (ICV) frame elements of the unit; $\psi_{11}, \psi_{12}$ - front wheel steering angles against his tractor frame; $\phi_{k}$ - angles between lines of motionless shells, wheels and axles on areas of respective centers of mass ICV; $\theta_{k}$ - angles of these axes lines to destinations with front hinges ICV; $\delta_{1}$, $\delta_{2}$ - lines of angles to the axis direction of the rear hinges ICV; $\gamma_{k}$ - angles, forming longitudinal axis of the 
vehicle's axle motionless coordinate system; $F_{A 1}, F_{B 1}$ - forces which acting on the front and rear axle tractor; $F_{B 2}, F_{B 3}$ - forces which acting on the axis of the hopper and sowing

Consider the dynamic model of the plane-parallel motion of the MTU (Fig. 1) for which the equation of kinematic bonds has the form:

$$
\left\{\begin{array}{l}
\omega_{i}=s \dot{A}_{i} \sin \frac{\theta_{i}}{A_{i} B_{i}} ; \\
\theta_{1}=\operatorname{arctg}\left(\frac{\operatorname{tg} \psi_{11}}{1+0,5 \eta_{1} \operatorname{tg} \psi_{11}}\right) ; \\
\theta_{\mathrm{n}}=\gamma_{i}-\gamma_{n}-\delta_{n} ; \\
\delta_{i}=\operatorname{arctg}\left(\operatorname{tg} \theta_{i}\right) ; \\
s \dot{A}_{n}=s A_{n}+s \dot{A}_{n-1} \sqrt{\left(\cos \theta_{n-1}\right)^{2}+\left(\lambda_{n-1} \sin \theta_{n-1}\right)^{2}} ; \\
s \dot{B}_{i}=s B_{i}+s \dot{A}_{i} \cos \theta_{i} ; \\
s \dot{O}_{i}=s O_{i}+s \dot{A}_{i} \sqrt{\left(\cos \theta_{i}\right)^{2}+\left(\mu_{i} \sin \theta_{i}\right)^{2}} ; \\
\dot{\gamma}_{i}=\gamma_{i}+\omega_{i} ; \\
x \dot{A}_{i}=x A_{i}+s \dot{A}_{i} \cos \left(\theta_{i}+\gamma_{i}\right) ; \\
y \dot{A}_{i}=y A_{i}+s \dot{A}_{i} \sin \left(\theta_{i}+\gamma_{i}\right) ; \\
x \dot{B}_{i}=x B_{i}+s \dot{B}_{i} \cos \gamma_{i} ; \\
y \dot{B}_{i}=y B_{i}+s \dot{B}_{i} \sin \gamma_{i},
\end{array}\right.
$$

where $\quad \eta_{1}=\frac{C_{21} C_{22}}{A_{1} B_{1}} ; \mu_{i}=\frac{O_{i} B_{i}}{A_{i} B_{i}} ; \lambda_{i}=\frac{B_{i} A_{i+1}}{A_{i} B_{i}} ; s-$ pseudo coordinates of points of unit elements; $x, y-$ coordinates the elements of the unit; $i=1,2,3-$ number of elements in the unit, indicating the tractor and bunker; $n=2,3$ - number of elements in the unit, indicating bunker and seeder.

Speed of all points of a dynamic model of the MTU and angular velocities of all bodies (Fig. 1) are expressed through one speed - the speed of the left middle wheel. In consideration of nonholonomic mechanical system of two degrees of freedom, and given control angle $\psi_{11}-$ one [9]. Pseudo velocity $v_{c_{11}}$ may be choose as an independent coordinate. Then the dynamic equations for finding it will look like:

$$
\sum_{i=1}^{3} J_{i} \frac{\partial \omega_{i}}{\partial v_{A_{1}}} \dot{\omega}_{i}+\sum_{i=1}^{3} m_{i} \frac{\partial v_{O_{i}}}{\partial v_{A_{1}}} \dot{v}_{O_{i}}=F_{B_{i}}-\sum_{i=1}^{3} R_{B_{i}} \frac{\partial v_{B_{i}}}{\partial v_{A_{1}}}
$$

where $\quad F_{B_{i}}, R_{B_{i}}$ - modules and the driving force of the resistance movement (given to points $B_{i}$ ).

From equation (2), taking into account the control angle $\psi_{11}$, the dynamics equation is obtained:

$$
\begin{aligned}
& s \dot{A}_{1}=\frac{d s O_{1}}{\frac{d s A_{1}}{d t}} \cdot m_{1} s \ddot{O}_{1}-\left(\frac{d s B_{1}}{\frac{d s A_{1}}{d t}} \cdot\left(F A_{1}+F B_{1}\right)+\frac{d s B_{2}}{\frac{d s A_{1}}{d t} \cdot F B_{2}}+\frac{d s B_{3}}{\frac{d s A_{1}}{d t}} \cdot F B_{3}\right)+ \\
& +\frac{d s O_{2}}{\frac{d s A_{1}}{d t}} \cdot m_{2} s \ddot{O}_{2}+\frac{d s O_{3}}{\frac{d s A_{1}}{d t}} \cdot m_{3} s \ddot{O}_{3}+\frac{d \omega_{1}}{\frac{d s A_{1}}{d t}} \cdot J_{1} \dot{\omega}_{1}+\frac{d \omega_{2}}{\frac{d s A_{1}}{d t}} \cdot J_{2} \dot{\omega}_{2}+\frac{d \omega_{3}}{\frac{d s A_{1}}{d t}} \cdot J_{3} \dot{\omega}_{3} .
\end{aligned}
$$


Numerical equation (2) and (3) solve using SSKA "KiDiM" [10], GNU Octave, MatLab or other mathematical computing software or software package.

Perform theoretical study of mathematical models of the dynamics of plane-parallel movement MTU (2), (3) in the tractor classic layout for example tractor KHTZ-16131 and sowing aggregate APP-6.

In the case of manual control of the unit in manual mode, that is, without the use of motion control systems (for example, the GPS system), the trajectories of motion of its elements represent harmonic oscillations [5], the control angle varies according to the sinusoidal law [8]:

$$
\psi=0,2 \cdot \sin (0,5 t) .
$$

Schematic of the plane-parallel motion of the MTU when changing the angle of control by law (4) is shown in Fig. 2

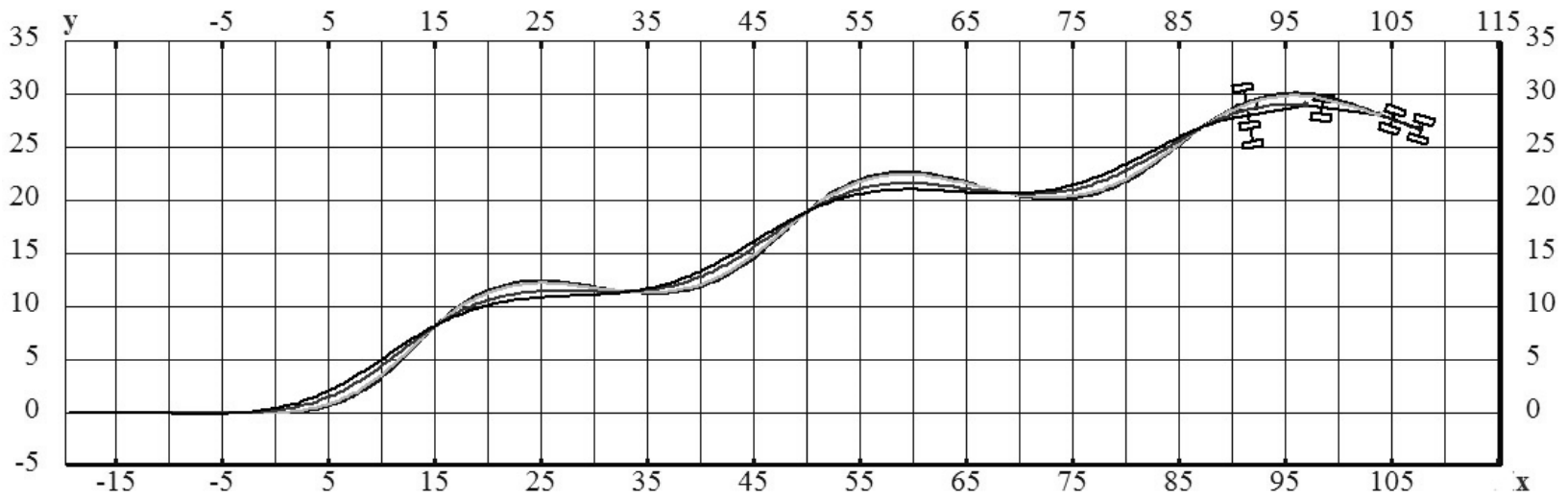

Fig. 2. Scheme of plane-parallel movement MTU
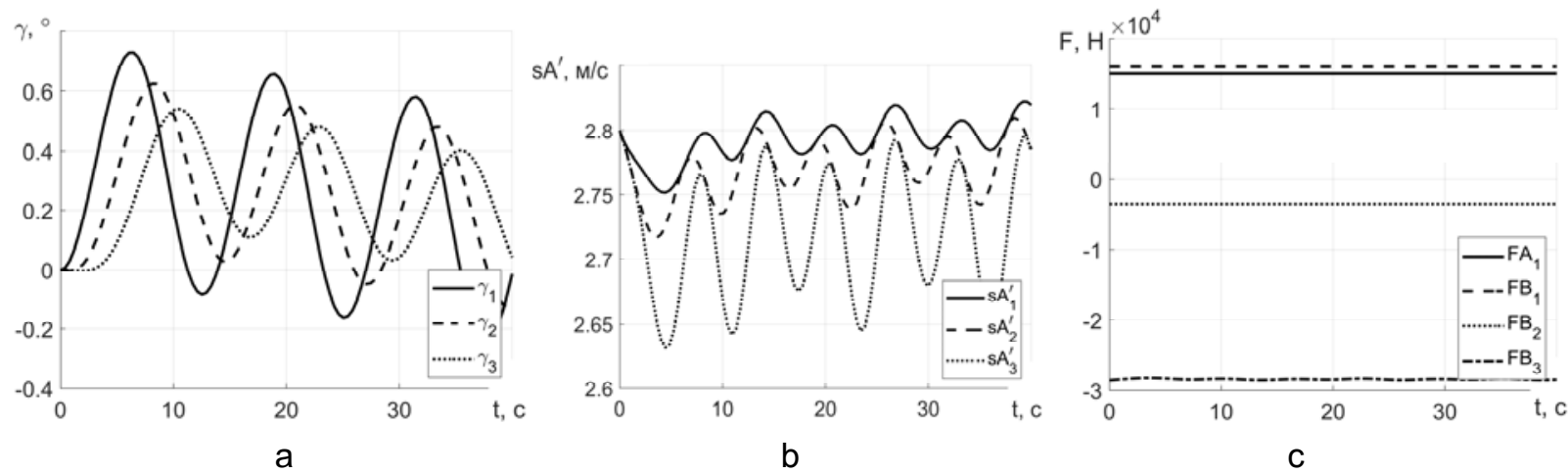

Fig. 3. Dependencies of the angles of rotation (a), velocities (b), and forces acting on the elements of the MTU (c) from time to time

MTA angles elements at an angle control $\psi=0,2 \cdot \sin (0,5 t)$ having a form of harmonic oscillations with a period $T=12 \mathrm{~s}$ and amplitudes $A_{\gamma 1}=0,7^{\circ}, A_{\gamma 2}=0,25^{\circ}, A_{\gamma 3}=0,2^{\circ}$ (Fig. 3, a).

Speeds of motion of the elements of MTU has a period $T=6 \mathrm{~s}$ (Fig. 3, b). The lowest average value of velocity $s \dot{A}_{3}=2,7 \mathrm{~m} / \mathrm{s}$ and the largest fluctuation $0.13 \mathrm{~m} / \mathrm{s}$ has a seeder. Average speed of the tractor and hopper are $s \dot{A}_{1}=2,8 \mathrm{~m} / \mathrm{s}$ and $s \dot{A}_{2}=2,77 \mathrm{~m} / \mathrm{s}$; fluctuation of $0.04 \mathrm{~m} / \mathrm{s}$ and $0.06 \mathrm{~m} / \mathrm{s}$. The forces acting on the elements of the aggregate at the points $A_{1}, B_{1}, B_{2}, B_{3}$ (Fig. 3, c) are calculated.

For experimental studies in Kharkiv Petro Vasilenko National Technical University of Agriculture developed measuring system dynamics and power of mobile machines [11]. 


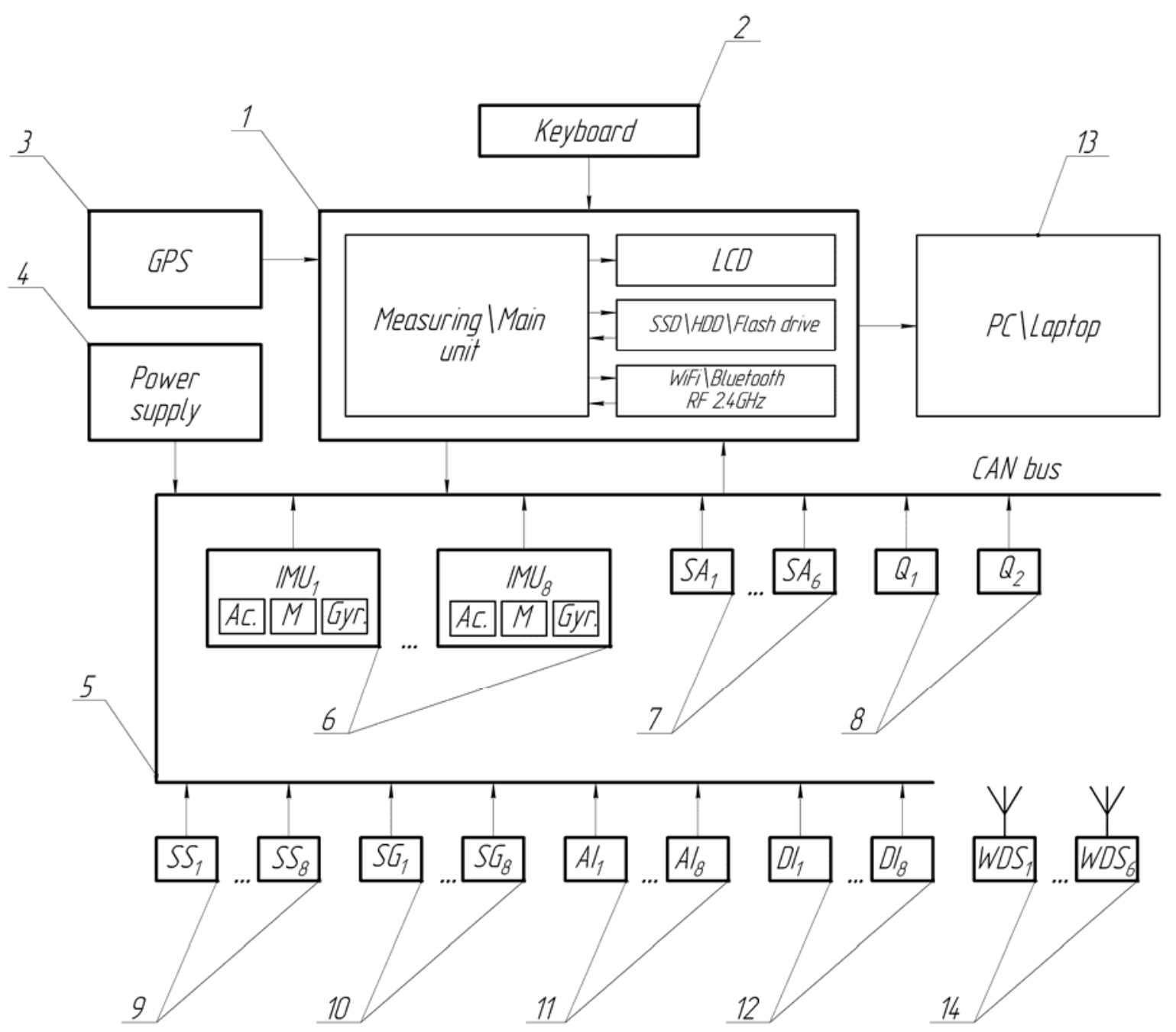

Fig. 4. Block diagram of the measuring system of dynamics and power of mobile machines

The developed measurement system related to the technical means of diagnosing and operational controls and can be used in agriculture and engineering industries. It is designed to determine the kinematic, dynamic and power characteristics of mobile machines and their components with road, field and bench testing.

The measuring system includes inertial measurement unit (IMU) 6, consisting of gyroscopes (Gyr.), magnetometer (M) and acceleration sensors (Ac), the navigation receiver (GPS) 3, rotational speed sensor (SS) 9, electronic dynamometers (SG) 10 analog (AI) 11 and discrete inputs (DI) 12, fuel meter (Q) 8. For measuring system developed software DASys PC Suite, which is responsible for storing information from sensors in the internal or external storage media. Communication between the sensors and computing modules occurs on the CAN-bus and 5 radio channels in the $2.4 \mathrm{GHz}$ band.

Innovative component of measuring system is a way to determine slipping wheel or driving sprockets. It is to determine the speed of rotation of wheels by means of gyroscope $\omega_{z}$ and accelerometer $a_{z}$, members of wheel dynamics sensors (WDS) 14, which is set in the center of the wheel. The angular rate gyroscope is measured angular velocity wheels $\omega_{z}=\omega_{k}$. When rotating tires, changing accelerometer signal $a_{z}$ perfectly, and the frequency of the signal is angular velocity wheels $\omega_{k}=f\left(a_{z}\right)$. Slipping wheels is given by:

$$
\delta=\frac{2 \cdot \pi \cdot r_{\partial} \cdot n_{\kappa}-v_{\partial}}{v_{\partial}} \cdot 100 \%
$$

where $n_{k}$-wheel speed, determined by the developed sensor, $\mathrm{s}^{-1} ; r_{\partial}$ - the radius of the wheel, as determined by ISO 4140-2002, ISO 4251-1:1992, $\mathrm{m}$; $v_{\partial}$ - actual speed that is determined by the receiver GPS, m/s. 
Experimental studies performed using the measuring system dynamics and power of mobile machines such sensors, inertial measurement unit, a navigation receiver GPS, sensor traction (electronic dynamometer) sensors and wheels dynamic.

Construct and compare the trajectory of the center of mass elements MTU received during experimental studies (Fig. 5).

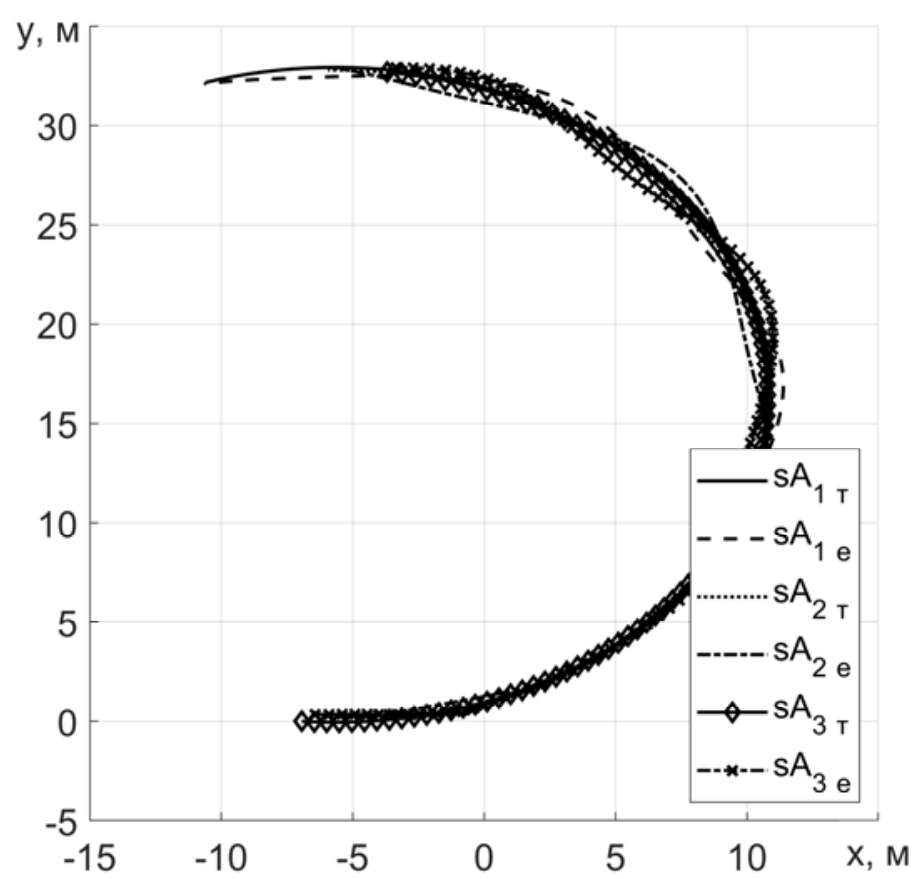

$s A_{1}, s A_{1 \mathrm{e}}$ - the trajectory of the tractor; $s A_{2 \mathrm{~T}}, s A_{2 \mathrm{e}}$ - the bunker trajectory; $s A_{3 \mathrm{~T}}, s A_{3 \mathrm{e}}-$ seeder trajectory; ( $T$ - the results of theoretical research, e - experimental studies)

Fig. 5. The trajectories of the center of mass elements MTU - KHTZ-16131 + APP-6

A fixed angle of rotation of the steering wheels tractor $\psi=10^{\circ}$ turning radius of MTU is $r_{\mathrm{p}}=16,25 \mathrm{~m}$. The discrepancy between the values of the trajectories of the tractor, hopper and sowing derived from experimental and theoretical research, not more than $4 \%$. Trajectory elements MTU is a complex parameter assessing the adequacy of a mathematical model of plane-parallel movement. Thus, the mathematical model of the plane-parallel movement MTU composed tractor classic layout can be considered adequate.

As a result of experimental studies compared theoretical $v_{m}$ and true $v_{\partial}$ the speed of the unit during the planting of cereal crops (Fig. 6, a) and determine skidding tractor wheels $\delta$ (Fig. 6, b).

The average value of the actual speed of the unit is $v_{\partial}=2 \mathrm{~m} / \mathrm{s}$ (Fig. 6, a). Average slipping $\delta=5 \%$; maximum value $\delta_{\max }=11,5 \%$ corresponding to the agro-technical requirements. 

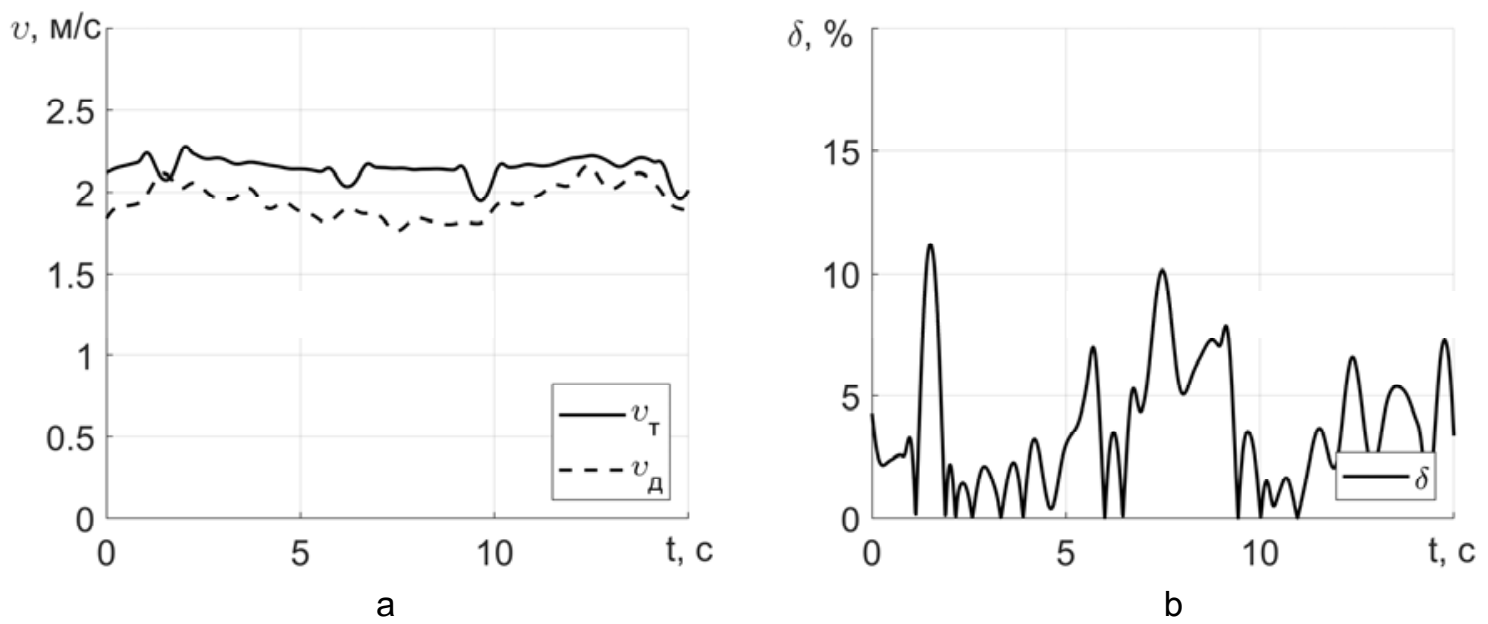

$v_{m}$ - theoretical speed; $v_{\partial}$ - actual speed; $\delta$ - slipping of tractor wheel

Fig. 6. Dependence of the speed of the MTU - KHTZ-16131 + APP-6 (a)

and slipping of tractor wheel (b) of the time

Dynamic indicators of MTU in the tractor KHTZ-16131 and direct-seeding seed drill APP-6 were obtained. The unit operates in satisfactory conditions of slipping $\delta=5$ and a maximum value $\delta_{\max }=11,5$; and the turning radius of the unit at the end of the rut $r_{p}=16,25 \mathrm{~m}$ which is smaller than its length kinematic $I_{\mathrm{K}}=18 \mathrm{~m}$.

\section{Conclusions}

Three mass dynamical models of flat-parallel movement of a multi-element machine-tractor unit are made on the example of a sowing unit in the classical tractor of the KhTZ-16131 and soil-cultivating unit APP-6. Found that the speed of all points of a dynamic model of tractor unit and angular velocities of all bodies can be expressed in terms of the speed of the left middle wheel. Dynamic model has one degree of freedom. MTU angles elements at an angle control $\psi=0,2 \cdot \sin (0,5 t)$ having a form of harmonic oscillations with a period $T=12 \mathrm{~s}$ and amplitudes $A_{\gamma 1}=0,7^{\circ}, A_{\gamma 2}=0,25^{\circ}, A_{\gamma 3}=0,2^{\circ}$. Motion speed of elements MTU has period $T=6 \mathrm{~s}$. The lowest average value of velocity $s \dot{A}_{3}=2,7 \mathrm{~m} / \mathrm{s}$ and the largest fluctuation $0.13 \mathrm{~m} / \mathrm{s}$ is for seeder. Average speed of the tractor and seed hopper $s \dot{A}_{1}=2,8 \mathrm{~m} / \mathrm{s}$ and $s \dot{A}_{2}=2,77 \mathrm{~m} / \mathrm{s} ;$ fluctuation of 0.04 $\mathrm{m} / \mathrm{s}$ and $0.06 \mathrm{~m} / \mathrm{s}$. During experimental studies MTA - KHTZ-16131 + APP-6 found that the unit operates in satisfactory conditions of slipping $\delta=5 \%$ and a maximum value $\delta_{\max }=11,5 \%$. Turning radius of the unit at the end of the rut $r_{p}=16,25 \mathrm{~m}$ which is smaller than its length kinematic $I_{\mathrm{K}}=18 \mathrm{~m}$.

\section{References}

1. Kjurchev V. M. (2014). Povorotkist MTA na osnovi orno-prosapnogo traktora. Mehanizacija ta elektryfikacija silskogo gospodarstva: Mizhvidomchyj tematychnyj naukovyj zbirnyk. NNC «IMESG». Glevaha. Vyp. 99. T. 2. S. 177-185. [in Ukrainian].

2. Lebedjev A. T., Kalinin Je. I. (2010). Dynamichna model gruntoobrobnyh mashynno-traktornyh agregativ z pasyvnymy robochymy organamy u skladi energetychnogo zasobu zi zdvojenymy shynamy. Systemy obrobky informacii. № 2(83). S. 109-115. [in Ukrainian].

3. Jaroshenko P. M. (2008). Matematychna model kombinovanogo posivnogo agregatu. Visnyk Sumskogo nacionalnogo agrarnogo universytetu. Sumy. Vyp. 3 (19). S. 62-66. [in Ukrainian]. 
4. Antoshhenkov R. (2013). Teoretycheskye yssledovanyja dynamycheskoj modely kolesnogo traktora klassa $30 \mathrm{kN}$. MOTROL. Commission of motorization and energetics in agriculture: Polish Academy of sciences. Lublin-Rzeslow. Vol. 15. № 7. P. 171-176. [in Ukrainian].

5. Nadykto V. T. (2003). Osnovy agregatirovanija modulnyh jenergeticheskih sredstv: monografija. Melitopol: KP «MMD». 240 s. [in Russian].

6. V. Adamchuk, I. Petrychenko, M. Korenko, H. Beloev, B. Borisov. (2015). Study plane-parallel motion movement combined seeding unit. III International scientific and technical congress agricultural machinery. Proceedings. Varna. Vol. 1. PP. 7-11.

7. Pavljuk A. S., Poddubnyj V. I., Valekzhanin A. I. (2008). Modelirovanie dvizhenija sharnirnosoedinennoj kolesnoj mashiny $\vee$ Matlab-Simulink. Vestnik Altajskogo gosudarstvennogo agrarnogo universiteta. № 8(46). S. 66-71. [in Russian].

8. Antoshhenkov R. V. (2017). Dynamika ta energetyka ruhu bagatoelementnyh mashynno-traktornyh agregativ: monografija. Kharkiv: HNTUSG. 244 s. [in Ukrainian].

9. Antonjuk E. Ja., Matyjasevych V. M. (2002). K teoryy dvyzhenyja sochlenennogo mnogozvennogo avtopoezda. Prykl. mehanyka. T. 38. № 7. S. 138-144. [in Russian].

10. Andreev Ju. M. (2007). Chislenno-analiticheskoe reshenie obratnoj zadachi dinamiki diskretnyh sistem. Vostochno-evropejskij zhurnal peredovyh tehnologij. № 2/4 (26). S. 10-13. [in Russian].

11. Antoshhenkov R. V., Antoshhenkov V. M.; (2014). Pat. 92889 Ukraina, MPK V60K 31/00, G05D 3/00. Vymirjuvalna systema dynamichnyh ta tjagovo-energetychnyh pokaznykiv funkcionuvannja mobilnyh mashyn / zajavnyk Antoshhenkov R. V., Antoshhenkov V. M. — № u 2014 03215; zajav. 31.03.14; nadruk. 10.09.14, Bjul. № 17. 